\title{
Family Support as a Fertility Factor in Russia
}

\author{
Kulkova I.A. \\ Dept. of regional socio-economic systems development \\ Institute of Economics of the Ural Branch of the Russian \\ Academy of Science, \\ Dept. of Management \\ Ural State University of Economics \\ Yekaterinburg, Russia \\ i.a.koulkova@mail.ru
}

\author{
Sharin V.I. \\ Dept. of Labor Economy and HR-Management \\ Ural State University of Economics, USUE \\ Yekaterinburg, Russia \\ Sharin_vi@usue.ru
}

\begin{abstract}
The study is aimed at studying the influence of the family and kinship support factor on fertility and parenting. The purpose of the study was to establish the value of family and family support for reproductive moods based on a study of fertility factors. In the course of the study, the authors used systems analysis methods and general scientific methods. The article presents the results of a fertility age women' survey about fertility factors conducted by the authors in Sverdlovsk region. As a result of the study, the authors concluded that the older parents help has not lost its relevance in Russia, despite the fact that there is a transition from the traditional patriarchal to the European family model. The availability of the older generation help has an important influence in the decision-making process about birth and raising a child.
\end{abstract}

Keywords-family-related support; family planning; childbirth; parenting.

\section{INTRODUCTION}

Russia is experiencing demographic difficulties today, like many European countries. So the birth rate is 1.62 children per woman, while, it should be 2.1 children to reproduce generations in society. There is a transition to the European family model in Russia at the present time. The mother's age is constantly growing, extramarital unions and children born out of wedlock are spreading, the number of children in families is falling. And the reason is not the existence of any barriers, but the fact that women are not only family oriented but also career oriented, they do not intend to have large families: only a third part of surveyed women want to have two or more children, many do not want have children at all [1].

The Concept of the demographic policy in Russian Federation for the period up to 2025 (Approved by President of Russian Federation Decree in October 9, 2007 No. 1351) indicates factors that adversely affect the birth rate, such as: low income of many families, lack of high living conditions, modern families structure (targeting small families, increasing the number of single-parent families), hard physical labor of a significant proportion of working women (about 15 percent), working conditions that do not meet sanitary and hygienic standards, low reproductive health, high number of pregnancy interruptions (abortion)
The measures taken by the government to raise the birth rate are insufficient. The structure of family policy mechanisms is characterized by the prevalence of economic measures, but the sum of government spending on supporting families with children, including "maternity capital", is 2 times less than in developed countries and amounts to $1.5 \%$ of Gross Domestic Product.

Support in the family and family circle acts as a noneconomic, social birth factor. According to scientists, for example, D. Bulanova. [2], Tarchenko V.S. [3], Parakhonskaya G.A. [4] older people — grandparents who have grandchildren - help them grow up in more than a third of families (from 33\% to 37\%), and also help financially (from $21 \%$ to $33 \%$ ).

Based on the issue relevance, a research task has been set: to establish the importance of family-related support in the planning, birth and upbringing of children on the basis of the fertility factors analysis.

\section{FERTILITY FACTORS: A THEORETICAL ASPECT}

The increasing the birth rate is the government's task in the most states in the world. The measures that are taken to solve this problem are universal in many respects and, as a rule, are implemented in three directions. These are: financial incentives (birth bonuses, child benefits, paid parental leave and tax breaks); support for parents in combining professional and family responsibilities (development of institutions providing care for young children, providing opportunities for part-time employment and flexible working hours) and social support for children and parents in all social institutions [5].

According to O. Kalachikova, a set of measures aimed to increasing the birth rate in Russia is similar to most European states. The measures are aimed to compensating the family's material expenses for the birth and children upbringing, the ability to combine the labor and family reproductive activities [6].

Russia has a system of allowances and benefits, tax benefits related to the number and order of childbirth, a legal framework regulating the mothers' labor activity is formed (the possibility of reducing the working day with a proportional change in wages, the duration of paid leave for 


\section{MethodOLOGY}

disability due to pregnancy, childbirth, child care, their inclusion in the length of service), as well as the infrastructure of parenthood and childhood (a network of public medical, educational and cultural provisions). Surveys conducted by scientists show that existing measures are not sufficiently attractive for the growth of reproductive moods. The respondents mainly note the following factors: an increase in their own housing (subsidies, interest-free housing loans), changes in labor legislation (an increase in the length of paid holidays and flexible forms of employment), the possibility of free access to pre-school educational infrastructure (nursery, kindergartens) [7], as well as an increase in cash payments for the child, the promotion of family values [8].

Obviously, when creating a family, and even more when babies are born, the factor of "separate from relatives housing" plays a decisive role; and then flexible forms of employment, the device of a baby in a nursery, a kindergarten become very important, so as not to lose work as a source of livelihood and professional realization.

A wider range of factors contributing to an increase in fertility, according to female respondents, is reflected in Table I.

TABLE I. OPINION OF RESPONDENTS ABOUT TARGETED MEASURES FOR IMPROVING THE FAMILY LIVING CONDITIONS, NECESSARY FOR RISING THE BIRTH RATE (\% ANSWER OPTIONS)

\begin{tabular}{|l|c|}
\hline \multicolumn{1}{|c|}{ Birthrate Measures } & $\%$ \\
\hline Subsidies for young families to purchase housing & 91.4 \\
\hline $\begin{array}{l}\text { Increase in the amount of benefits for each child and social } \\
\text { benefits to mothers at birth }\end{array}$ & 78.1 \\
\hline Having a full family, good family relationships & 61.1 \\
\hline $\begin{array}{l}\text { Subsidies to pay for the maintenance of children in } \\
\text { kindergartens }\end{array}$ & 52.0 \\
\hline Tax benefits for working mothers and fathers & 51.4 \\
\hline Partial changes in labor law & 36.9 \\
\hline $\begin{array}{l}\text { Payment of maternal labor, taking into account the work } \\
\text { experience }\end{array}$ & 12.3 \\
\hline Older parents' help in raising children & 8.4 \\
\hline Prohibition of abortion & 2.7 \\
\hline Other & a. Compiled by [9] \\
\hline Find difficulties to answer & \\
\hline
\end{tabular}

The data of the table show that the most significant factors for the birth of children for respondents are factors of both economic and social, family nature. These are: subsidies to young families for the purchase of housing, an increase in the size of benefits and social benefits, the presence of a full family, good family relationships, changes in labor laws that improve employment conditions in connection with the birth of a child. The measures that support fertility, the respondents attributed the help of older parents in raising children.
The intention to have one more child is subjective, consequently the study of factors affecting fertility is traditionally made by using a sociological method. Population surveys [10], [11], observations [12] or panel studies [13] are usually conducted for this purpose.

The authors have conducted a study using their own survey tool - a questionnaire. 107 women have been surveyed in total, $58 \%$ of whom are girls aged $18-24$, and $42 \%$ women aged $31-$ 47 years. The survey was conducted mainly in Sverdlovsk region. A question was asked about the each of the factor's importance in deciding to give birth to a child.

\section{THE FAMILY AND KINSHIP SUPPORT IMPORTANCE IN THE PROCESS OF PLANNING, BIRTH AND UPBRINGING CHILDREN}

Despite the changes in the public consciousness regarding family and parenthood, Russia still remains a country with traditional views, to a large extent, on many issues in this sphere. This also applies to family and family support during birth and parenting.

To determine how strong is grandparents' support as the influence factor on the decision to give birth to a child, the authors conducted a sociological survey of fertility women. The survey results are presented in Table II.

TABLE II. DISTRIBUTION OF RESPONDENTS' ANSWERS ABOUT THE STRENGTH OF THE INFLUENCE FACTORS ON FERTILITY, \%

\begin{tabular}{|c|c|c|c|c|}
\hline Birthrate factor & $\begin{array}{c}\text { Strong } \\
\text { effect }\end{array}$ & $\begin{array}{c}\text { Medium } \\
\text { effect }\end{array}$ & $\begin{array}{l}\text { Weak } \\
\text { effect }\end{array}$ & $\begin{array}{c}\text { Has no } \\
\text { affect }\end{array}$ \\
\hline 1. Spouses' love & 82.4 & 11.8 & 3.9 & 2.0 \\
\hline $\begin{array}{l}\text { 2. The separate housing } \\
\text { availability }\end{array}$ & 52.9 & 25.5 & 13.7 & 7.8 \\
\hline 3. High family affluence & 29.2 & 39.6 & 16.7 & 14.6 \\
\hline 4. The grandparents' support & 27.7 & 27.7 & 25.5 & 19.1 \\
\hline $\begin{array}{l}\text { 5. Sufficient number of } \\
\text { kindergartens }\end{array}$ & 13.0 & 32.6 & 37.0 & 17.4 \\
\hline $\begin{array}{l}\text { 6. The real benefits for parents with } \\
\text { more than } 1 \text { child from the state }\end{array}$ & 12.5 & 27.1 & 33.3 & 27.1 \\
\hline 7. Maternity capital & 8.5 & 31.9 & 42.6 & 17.0 \\
\hline
\end{tabular}

According to the survey results, the most powerful factor influencing the decision to give birth to a child is the love between spouses (partners): $82.4 \%$ of respondents noted that this factor influences strongly. At the second place in terms of influence power is the separate housing availability factor. He was noted as a strong factor by $52.9 \%$ and another $25.5 \%$ noted him as a factor with a medium influence level. The third place is occupied by the high family affluence factor: $29.2 \%$ of the respondents noted that this factor is strong, and $39.6 \%$ noted that it is medium.

The grandparents' support studied by the authors is on the fourth place in terms of the impact on the decision to give birth to a child: equally for $27.7 \%$ noted its strong and medium impact, and another $25.5 \%$ of respondents noted its influence but in a weak form. The remaining factors proposed 
decrease in the family's social importance. It leads them to abandon the traditional grandparents' functions, preferring them professional activities.

Meanwhile, how "profitable" the grandmothers help as a subject of kinship support depends on the extent to which the older family members' career and experience generate income and status for them personally and for the family as a whole. Researchers have noted an increase of people of the "third age" in the intra-family financial significance; they support the younger generations financially, continuing their professional activities, including during retirement. More often, the modern grandmother assumes the role of a "visiting tutor" nowadays and has sporadic recreational activity, combining this with the material support of grandchildren. The type resembling the French "grand mere" rather than the Russian grandmother is becoming more common [17].

The retirement age raising can affect fertility. It is not possible to assess currently the magnitude of this phenomenon, since increasing the retirement age is gradual, but the consequences forecast is possible. According to VCIOM polls, the main pensioners' motive for continuing work is the insufficient pension (81\%, for megacities - 91\%). On the second place is the desire to help children and grandchildren financially - 36\%. Other reasons are the habit to work, the desire to avoid loneliness, interest in work - 22$28 \%$.

The older generation's support reaches the maximum level from the moment the grandmother retires, that is, 55 years old in Russia. It corresponds to the grandchildren' age up to 11 years on average, when assistance in caring for the child and upbringing is most in demand. Grandmother's age from 65 years is estimated as the period of the older and younger generations separation. Raising the retirement age up to 60 will reduce the age of active interaction between the older generation and grandchildren by 5 years in the most important period for support. An increase the receiving grandmother's care period by 5 years may be a significant reason to delay the birth of a child until the older generation retires. In addition, women who retire at an older age may not be able to provide childcare assistance for health reasons. An increase in the retirement age established by the state can cause a significant jump in the level of population disability.

Grandmother's age of 65 years is estimated as the period of the older and younger generations separation. Raising the retirement age to 60 years will reduce by 5 years the age of active interaction between the older generation and grandchildren in the most important period to help. An increase in the period for receiving parental care for childcare by 5 years may be a significant reason to postpone the birth of a child until the older generation retires. In addition, women who retire at an older age may not be able to provide childcare assistance for health reasons. Raising the generally established retirement age can cause a significant jump in the level of the population disability.

First of all, raising the retirement age will negatively affect the motivation to give birth, for the most part, to second and third children, the number of which and their share in the total number of births determines the achievement of an expanded independence of the young family, people of the "third age" 
or even simple replacement of the parents' generation by the children generation. It will minimize the depopulation process in the country. In the aspect of the support forms transformation, the material forms significance will increase. Older generation's longer employment will lead to a potential opportunity to increase material forms of support, but will reduce the possibility of direct participation in child care and upbringing assistance. It is significant that according to the study results [18] about demographic policy measures assessment (in decreasing order of importance in solving the problem of increasing fertility), the respondents have attributed the reduction in the retirement age (inversely to the number of children) to the most effective measures for increasing the birth rate (third place).

\section{CONCLUSION}

The growth of separated families, especially in cities, an increase in the age of being on the labor market and women' professional ambitions, an increase in the retirement age, a decline in the role of traditional family values, and other factors led to a change in the forms of support by the older generation. Serious changes are expected as a result of the retirement age increasing in Russia [19]. The development or absence of a child's preschool infrastructure in state or/and private forms, the "nannies" institute will also make its own adjustments to the forms of support by older parents, as well as the place of residence - in rural areas the traditional forms of extended family and family assistance will remain relevant for a long time.

The main one is the tendency to change the family-related assistance forms - from only services to material assistance and services (as needed). Meanwhile, intergenerational relations are at a fairly high level in Russia at present, many families prefer traditional family relationships, including mutual support. It can be concluded that the older parents' assistance has not lost its relevance and still remains one of the essential factors in making decisions about the child birth and upbringing. Possible areas for further research include a change in the forms of family support provided by older parents in raising their children, due to an increase in the retirement age in Russia.

\section{Acknowledgment}

The reported study was funded by RFBR, project number 19-010-00545\19 "The impact forecast of the retirement age increasing on the birth rate in Russia”

\section{References}

[1] I.L. Zhuravleva and Y.A. Gavrilova, "Analysis of factors of fertility in Russia: what do the HSE RLMS data show?” Economic journal, 2017, vol. 21. No. 1, pp. 145-187.
[2] D.D. Bulanova, "The role of the older generation in the education of preschoolers”, Scientific reflection, 2017, No. 4 (8), pp. 9-11.

[3] V.S. Tarchenko, "The role of the older generation in the preservation of traditional family values (on the example of the Republic of North Ossetia-Alania)”, Bulletin of the University, 2016, No. 11, pp. 256-259.

[4] G.A. Parakhonskiy, "Elderly person in the family", Sotsiologicheskiye issledovaniya (Sociological research), 2002, No. 6, pp. 103-110.

[5] P. McDonald "Sustaining fertility through public policy: The range of options”, Population (English version), 2002, No. 57 (3), pp. 417-446.

[6] O.N. Kalachikova, Trends and prospects of reproductive behavior of the population (on the example of the Vologda Region). Abstract. Thesis ... Cand. of Econ. Scien. M., 2013.

[7] S.A. Sycneva, "Modern trends of fertility in the Republic of Sakha (Yakutia)”, Standard of living of Russian regions, 2017, № 2 (204), pp. 51-57.

[8] V.N. Arkhangel'skiy, Fertility factors, M.: TEIs, 2006.

[9] Ya.A. Sryabina, The characteristics of the population's reproductive behavior in the conditions of the transformation of the Russian economy. Abstract. Thesis ... Cand. of Econ. Scien. Yekaterinburg, 2011.

[10] M. Goleva and I. Pavlyutkin, “Social Networks and Fertility”. Journal of Economic Sociology - Ekonomicheskaya Sotsiologiya, 2016, 17 (1), pp. 83-98.

[11] Y. Youm and B. Lee, "A network approach to economic models of fertility. Rationality and Society”, 2016, 28 (4), pp. 386-409.

[12] C.C.M. Beerendonk, O. Baysal, J. Koetsenruijter, et al. "Introduction of social network analysis into the field of fertility preservation”. In: 31st Annual Meeting of the European-Society-of-Human-Reproduction-andEmbryology (ESHRE). Human Reproduction, 2015, 30 (1), pp. 317-318.

[13] D. Lois and O.A. Becker, "Is fertility contagious? Using panel data to disentangle mechanisms of social network influences on fertility decisions”. Advances in Life Course Research, 2014, 21 (SI), pp. 123134.

[14] D.H. Ibragimova, "How much does the Russian grandmother "cost"?" Parents and children, men and women in the family and society: Collection of analytical articles, vol. 1 / Ed. T.M. Maleeva and O.V. Sinyavskayam, Moscow: NISP, 2007, pp. 623-637.

[15] O. Sinyavskaya and E. Gladnikov, "Adult children and their parents: the intensity of contacts”, Demoscope Weekly, 2007, № 287-288. URL: http://demoscope.ru/weekly/2007/0287/index.php.

[16] Y. Gorlin, V. Lyashkov and T. Maleeva, "Raising the retirement age: the positive effects and possible risks”, Economic policy, 2018, vol.13, No. 1, pp. 148-179.

[17] I.I. Korchagina and L.M. Prokofieva, "Population of Russia: on the role of society and family in supporting children and the elderly". Parents and children, men and women in the family and society: Collection of analytical articles vol. 1 / Ed. T.M. Maleeva and O.V. Sinyavskayam, Moscow: NISP, 2007.

[18] I.P. Voiku, O.N. Kopytova and I.S. Smirnova, "Non-traditional measures to increase birth rates and assess the likelihood of their use", Young Scientist, 2016, No 12, pp. 1182-1193.

[19] V.I. Sharin, "Systematization of the possible negative consequences of raising the retirement age in Russia”, Human Progress, 2019, vol. 5, issue 5, p. 9.

[20] Kalakov, N.I., Neverkovich, S.D. Conception of civilized - integrated prognostic upbrining among youth in order to archieve the development peak of the Russian society universalization. The Russian Journal of Physical Education and Sport. 2018, vol. 13(1), pp. 60-70. DOI: 10/14526/01_2018_286. 